\title{
Parking inventory management: a logistics perspective in urban traffic congestion mitigation
}

\author{
V. Fiorillo \& R. Secchi \\ Technology and Operations Management Unit, \\ SDA Bocconi School of Management, Italy
}

\begin{abstract}
With the introduction of Travel (or Transportation) Demand Management (TDM), literature widely agreed that mobility is a matter of managing the demand side, especially in urban areas where accessibility has hardly modifiable physical constraints. In this context, the improvement of parking management is one of the main drivers for managing the demand side of transportation: design, location, pricing and enforcement of parking directly impact on traffic. Congestion is, in fact, caused by the imbalance between demand and supply and the lack, or mismanagement, of parking accounts for a considerable share of this: Shoup (Cruising for Parking, Transport Policy 2006) concludes that vehicles "cruising" for an available parking generate at least $8 \%$ of the total traffic. In a logistics perspective, this share of congestion is caused by the decoupling between stocks (available parking), scattered within a decentralized network of warehouses with fixed capacity (parking lots), and flows (traffic) representing a poorly predictable demand. Tackling traffic congestion in urban areas may thus be seen as a logistics problem of inventory management. The aim of this paper is to introduce a new research stream in the field of TDM by applying logistics principles and tools to the matter of parking management. Further research will involve the collection of empirical data to measure the intensity of this relation, and to explore the possibility of individuating the decoupling point beyond which available parking will stock out.
\end{abstract}

Keywords: logistics, parking management, urban traffic, congestion, transportation demand management, inventory management, stock, flows. 


\section{Introduction}

Most European citizens live in densely populated urban areas. Their lives largely depend on the ease of moving and reaching destinations within the infrastructure network they share. The issues related to urban mobility not only affect the quality of life of citizens, but also the environment and the economy. According to the European Commission, urban mobility accounts for $40 \%$ of all $\mathrm{CO}_{2}$ emissions of road transport and up to $70 \%$ of other pollutants from transport. Moreover, about $85 \%$ of European GDP is produced within urban areas making them the engine of European economy, nourishing entrepreneurial dynamism, drawing investments and employment.

Traffic congestion is located in and around urban centers and accounts for $1 \%$ of EU GDP, approximately 100 billion Euros per year. Thus, the reduction of traffic congestion should be the priority at top of the list not only for its social and environmental desirable outcomes but, even before, for a mere economic reason [3].

Congestion of the system is caused by many different factors such as users travel behavior, physical constraints, system design flaws and services inefficiencies. From a higher point of view though, congestion is caused by imbalances between demand and supply. Commonly, demand is referred to as the "transportation demand" generated by people willing to travel. On the other side, supply consists of road and parking capacity, public transportation and other services made available to the users. Since every car trip begins and ends inside a parking space, the capacity of the supply side largely depends on the availability of parking areas at destination. As shown by many authors [4-6], inadequacy and mismanagement of parking facilities will cause congestion to rise.

For decades of the last century, under the old car centric conception, urban planners expanded parking capacity at the spite of street space, recreational and green areas. On-street parking especially, accounting for a considerable share of congestion [2], brings more externalities than benefits.

The current paradigm based on Travel Demand Management [7], managing existing facilities, rather than building new infrastructures, has led to concentrating the efforts on the prediction of traffic flows for the optimization of infrastructures. Nevertheless, the continuous increase of demand and its intrinsic high unpredictability limited the application of forecast tools, making parking expansion irreversible.

Focusing on congestion generated by curbside parking and external costs it brings, we present in this paper a perspective overturning. With the introduction of logistics and supply chain management principles in the management of urban mobility infrastructures, we shift the attention from car flows to parking stocks, widening the range of possible solutions to tackle external costs caused by curbside parking spaces. Considering the large diffusion of roadside parking areas, we will take Italy as an emblematic example, to support the proposed research framework. 


\section{Parking management and curbside parking}

In order to mitigate congestion and create more livable urban environments, TDM embraces a wide array of strategies and tools: from fostering public transportation to the definition of better policies, from designing and planning of urban infrastructures to the incentives to alternative transport modes. Of all tools of TDM, parking management, modifying conditions at the destination, is a relevant component of the demand management for congestion reduction.

The importance of parking management to tackle urban traffic congestion derives directly from three simple considerations: 1) the allocation of time between movement and parking of vehicles is heavily imbalanced towards this latter: a car is used, on average, only for two hours a day, while the other 22 stands in a parking stall [8]. 2) In the central areas of the city, only 10 of 100 vehicles are in motion [8]. 3) The use of the car as a travel mode far exceeds all others, at least in Italian cities, with more than $90 \%$ of people using car for daily trips [9].

Once a comparatively neglected area of research within TDM policy, the study of parking is now receiving considerable attention as policy makers and researchers recognize the pivotal role that parking spaces and their regulation play in shaping the urban, mode choice, congestion, economy and our environment [4].

Parking Management (PM hereafter) refers to the offer, the price and the regulation of parking facilities [5]. PM significantly impacts on travel behavior: if parking becomes more affordable and available, the number and usage of private cars generally increases [6, 10-12].

PM represented a paradigm shift in how to identify problems and evaluate possible solutions: under the old car-centric conception, motorists should always be able to find easy and free parking everywhere. Managing parking consisted primarily in the creation of parking set to satisfy demand peaks sinking the cost in taxes, rents or the price of goods and services providing free parking [6].

The figures for parking facilities designation in Italy have revealed themselves to be highly underestimated against a steadily growing number of cars. Today this number has reached an average of 614,8 cars per 1000 inhabitants in all major Italian cities [13]. With families now possessing more than one car, the common costume is to leave the second (or even the third car) in on-street parking areas.

Self-contained parking facilities are required for a good city road traffic system and if the capacity of these facilities is insufficient, on-road parking and disorder parking will appear, which will further decrease traffic capacity. According to ACI-CENSIS report [9], in Italy today, the most common violation on streets is no-parking violation $(27,8 \%)$, closely followed by double parking $(21,7 \%)$ which is a direct consequence of overcrowded curb parking spaces.

In spite of most of the urban planning manuals, curbside parking is widely diffused, especially in major Italian cities. Since delimiting parking areas at road side is a fast and non expensive way to create new parking capacity, the tendency, especially in the past, was to occupy all available space on roadway to 
ease parking for the ever growing number of cars, at the expenses of valuable recreational and green areas. This kind of parking, however, generates externalities resulting in an inefficient use of urban spaces and in the increase of traffic congestion $[2,5,14]$.

Motorist driving in search of an available curb parking space often make up a significant share of total traffic: according to a quantitative study on underpriced curbside parking-generated congestion, Shoup [2] concludes that cars cruising for an available parking space contribute to at least $8 \%$ of total traffic. According to Kodransky and Hermann [15], as much as $50 \%$ of traffic congestion is caused by drivers cruising around in search of a cheaper parking space. Curb parking is widely diffused in most cities of the world, and because it is cheap and its capacity is rigid towards an ever growing traffic demand, congestion caused by cars cruising for parking has been rising in the last decades.

\section{Managing cars flows: the TDM approach}

The current dominant paradigm in TDM has mainly focused on flow prediction and management. However, traffic flows are highly unpredictable since they comprise almost unlimited individual choices, based on an almost infinite number of sources and destinations. For decades, scholars and planners attempted to predict the traffic demand by applying mathematical models for flow forecasting and optimization of infrastructures [16]. More recently, efforts have focused on short term flow forecasting modeling and they constitute the basis for several traffic management technologies that fall under the name of ITS (Intelligent Transportation Systems). Despite the complexity and sophistication of the several models introduced over the years, their performance has always been relatively small and so has been, therefore, their effective application [17].

As for the rest of the urban infrastructure in the network, the quantification of the parking spaces on the street (not intended for residents, or rotation parking) is carried out on the basis of traffic flows prediction. Given the inability to forecast demand and the high variability from area to area and from period to period, the quantification of on-street parking for non-residents, is generally determined based on the average of peak demand [4].

Urban planning manuals usually suggest that the mean flow of cars transiting in a particular area within an hour is a good tool to determine the size of the parking facilities required $[8,18]$.

The focus on flows of cars, common in the disciplines that come under the TDM, the rigidity of the infrastructure to adapt to ongoing changes in the flows and the continuous increase in the number of vehicles, has led to a steadily growing shortage of parking places.

Chasing the unpredictable and growing traffic demand (and listening to the electorate), many municipalities have incurred in the well known "Braess's Paradox" over road infrastructures [19]: the improved accessibility resulting from the greater number of parking spaces and the price too low paid for parking [20] generates increased traffic demand [21] to the point where the new supply of parking facilities becomes insufficient again. Following the opposite idea of 
managing existing infrastructures, investments in urban mobility have lately focused on modeling traffic flows and implementing ITS to provide information on traffic conditions and dynamic pricing strategies in real time. This effort, however, clashes with the inevitable rigidity of structures, especially that of onstreet parking areas, subtracting space even if travel demand should fall to zero. Because the current paradigm for the design of parking areas based on the expected flows, also influenced by political choices, showed to be not very effective and brings with it side effects on the level of traffic congestion, the adoption of a different point of view, expanding management possibilities is desirable.

\section{From flows prediction to stock management}

A change of perspective is possible through the introduction of logistics principles into TDM. This merely means shifting from car flows to parking stocks. In this perspective, parking spaces become a "product", and the municipal authorities the "manufacturers" of this product. From this point of view the municipality providing parking areas acts as a vertically integrated manufacturing company storing its parking stocks in streets. The streets become warehouses, filled and emptied according to the individually rational choices of motorists. The focus on demand prediction, brought by TDM, pushes the municipality to build its inventory upon forecasts.

In manufacturing, when the production lead-time is greater than the delivery lead-time requested by customers, firms are forced to rely upon forecasts producing to build inventory. The so-called make-to-stock approaches, typically, tend to oversize capacity (and stocks) to keep an acceptable service level against any occurring demand peak [22]. High demand variability can only increase the risk of stock-outs and over-stocks. In managing parking areas, the municipality acts in a very similar fashion: since it is impossible to add parking areas in realtime when demand arises, parking slots are produced in advance, building inventory along the streets.

Inventory management is a central issue in operations management, and has accordingly received a considerable attention in literature. One of the drivers for this attention is that holding inventory represents a significant cost along the supply chain [23].

The shortfall of parking spaces in relation to the average of the peaks (mentioned above) indicates that parking slots stock-out during peak flows of inbound cars (stimulating not allowed parking behaviors). Conversely, since the focus was placed on the flow of cars, on-street parking rotation charges, following the "market", are often free during times of lower demand (nights and holidays, for example). In other words, the over-stock of parking spaces, dimensioned according to the average peak demand, is such as to make them worthless when demand falls below this level.

In a logistics perspective, the externalities created by the expansion of parking capacity becomes a matter of inventory that has been oversized, taking advantage of an apparently low holding cost. Since the uncertainty of demand exerts the 
greatest influence on the level of stocks [24], as a manufacturing company facing a volatile and unpredictable demand, the municipality maintains high stock levels to meet demand peaks.

Although easy to build, the excess inventory of on-street parking spaces brings high holding costs that are not covered by the cost of renting the space to motorists, and that go beyond the mere occupation of a space for a limited period of time. As mentioned in previous sections, the costs of on-street parking derive, first of all, from the scarcity of urban space, the variable portion of traffic congestion generated by motorists looking for parking, parking maneuvering, double row parking and the opportunity cost of using the road for other uses.

If we accept the idea that in order to increase public transport and sustainable personal mobility lanes (e.g. bike-lanes) it is necessary to remove parking from streets, from a logistics perspective this means reducing stocks. This latter consideration does bring another important implication.

The current TDM perspective, in facts assumes that demand is largely exogenous, but this is not completely true. Demand sensitiveness to parking prices is undisputed, but it does have such long term effects that traffic demand is still perceived as an exogenous variable. In our opinion, the physical stock of parking spaces does play a relevant role. Some studies show that in a retail market, physical stock levels at the point of sale significantly affect demand: the higher the levels of physical stock in the store, the greater the demand. Customers are attracted by the idea that the store offers a wide availability [25]. In the logic of responding to flows of vehicles, the size of the parking stock is large by necessity, but (in this case) this causes the side effect of increasing the perception that parking is abundant, regardless of price.

\section{Implications}

Through the logistics' tool of inventory management, it is possible to study and address the problem of on-street rotation parking from another perspective extending the range of available tools to those inherent to logistics and supply chain management. By introducing the concept of parking stock, in our opinion, on-street parking spaces can be managed in a more complete and efficient way, taking into account inventory holding costs to redistribute parking allocation across the urban area.

\subsection{Forecast inaccuracy vs. stock/price driven demand}

The chaotic nature of the traffic demand makes forecasting tools, however sophisticated, inaccurate. The approach to the management of on-street parking in response to the demand forecast is therefore fallacious. The elasticity of demand to price and physical stock of parking, suggests that it is more appropriate to start from stock management to mitigate the adverse effects of congestion caused by on-street parking. If from the perspective of flows it is uneconomic to reduce parking, a reduction in the inventory of stocks is feasible and desirable. Reducing the cost of inventory carried by the urban community 
should more than compensate the inconvenience caused to users accustomed to travel by car. At the same time, reducing inventory of on-street parking spaces, because it is a difficult to reverse structural decision, makes them a scarce resource, which requires a subsequent price increase commensurate with the costs and externalities.

\subsection{Externalities vs. holding costs}

Stock management in parking management means taking into account inventory carrying cost. The holding costs of on-street parking spaces are given by the negative externalities they generate. The tools available to manage the cost of holding inventory are effectively and efficiently applied in supply chain management and they do not only take into account the demand forecast but also the size of stocks itself. By introducing this new cost variable, the municipality can progressively "replenish" a lower number of items (parking spaces), thereby reducing the overall level of stocks and / or moving stocks where holding costs are lower (e.g. park and ride facilities at the outskirts of the city). The tools for stock management allow the design of on-street parking taking into account the hidden costs and they do not require a further complication of the models for the prediction of traffic flows, which are already very sophisticated and complex.

\subsection{City-wide parking management}

Inventory management tools may facilitate the integrated management of parking areas around the urban area, avoiding spot scattered and conflicting parking management solutions. TDM includes a wide range of tools and formalized strategies to reduce congestion by modifying users' travel behavior. Although the effect of TDM strategies is demonstrably cumulative and synergistic, it is often impossible to implement a comprehensive TDM policy [26]. Desirable integrated plans are often constrained by implementation and operational costs, political advisability and other tangible and intangible limitations. Hence, any new technology, design and managerial approach that can facilitate the progressive development of flexible TDM plans have to be pursued, overcoming the usual limited effectiveness of the patchy integration of single and independent solutions.

Through the integrated management of all parking stocks, it is possible to consider the holding cost of the total inventory. Not all kinds of parking areas imply the externalities, at urban area level parking areas appear as a network of warehouses with different holding costs. To reduce the total cost of inventory, stocks can be moved from a high holding cost warehouse (the road) to more peripheral infrastructures where costs are lower (underground parking lots, above ground parking, park and ride, parking terminals, etc.). Even if not through the lens of the stock management, an approach of this type has been used, for example, in Hamburg (DE), Zurich (CH) and Budapest (HU). In these urban centers upper limits of parking supply have been established in the city center through the reform (and then freezing) of the plan. In Hamburg, the roof level was fixed in 1976 and allows a maximum of 30,000 cars. In Zurich, the cap was 
established in 1996 and provides for a system of so-called "cap and trade": for each parking space built outside of the roadway, one will be removed from the street. This system allows to maintain unchanged the overall number of parking spaces and, at the same time, to implement redevelopment plans for the emptied portion of roadway [27]. Finally, in Copenhagen the same system was adopted to remove 1000 on-street parking spaces, for reuse as pedestrian and cycle paths, in exchange for 3000 off-road parking spaces created by a private developer [15].

\section{Caveat}

The perspective change introduced in this paper with the concept of parking inventory management does not take into account tangible and intangible aspects affecting parking usage, allocation and management.

In first place, any change in the parking management plan is a long term decision, whose benefits can only be measured in years. On the opposite, the number and allocation of parking areas according to traffic demand, regardless of externalities they bring, is often determined by short-sighted political choices. This influences the applicability of practices aimed at a better parking management. The research stream introduced by this paper, moreover, deliberately does not take into account the level and effectiveness of enforcement deployed to avoid parking violations and the service level of public transportation means. Nevertheless, it is recognized that enforcement and public transportation affect directly the applicability of parking management strategies and tools.

\section{Further research}

This introductive paper would be the first in an exploratory study of applicability and effectiveness of inventory costs in parking management for congestion reduction. Following research will involve the collection of empirical data to measure the intensity of the relation between parking stock and demand flows. Studies will focus on determining the existence of a decoupling point between stocks (available parking), scattered within a decentralized network of warehouses with fixed capacity (parking areas), and flows (traffic). This will allow testing of inventory management tools within parking management, possibly redistributing parking stocks according to holding costs and adapting parking price according to demand distribution over space and time.

\section{References}

[1] Zhou, J. Z., Hierarchy analysis and strategies on the imbalance between demand and supply of urban traffic. Journal of Transportation Systems Engineering and Information Technology, 4(7), pp. 24-29, 2007.

[2] Shoup, D., Cruising for Parking. Transport Policy 6(13), pp. 479-486, 2006. 
[3] Commission of the European Communities, Green Paper: Towards a new culture for urban mobility [COM(2007) 551 final], Brussels, pp. 3-5, 2007.

[4] Shoup, D., The trouble with minimum parking requirements. Transportation Research Part A: Policy and Practices, 7-8(33), pp. 549-574, 1999.

[5] Litman, T., Parking management: strategies, evaluation and planning. Victoria Transport Policy Institute. www.vtpi.org/park_man.pdf.

[6] Shoup, D., The High Cost of free parking. Journal of Planning Education and Research, 1(17), pp. 3-20, 1997.

[7] Nelson, D. C. (Ed.). Intelligent Transportation Primer, Institute of Transportation Engineers: Washington, DC, pp. 10-11, 2000.

[8] Brambilla, C. \& Cusumano, G., Progettare e realizzare $i$ parcheggi pubblici e privati. Maggioli Editore: Rimini, 1995.

[9] ACI, CENSIS, XVIII Rapporto ACI-CENSIS 2010, Automobile Club d'Italia: Rome, 2010.

[10] Morral J. \& Bolger D., The Relationship Between Downtown Parking Supply and Transit Use. ITE Journal, 2(66), pp. 32-36, 1996.

[11] Mildner, G.C.S., Strathman, J.G. \& Bianco, M.J., Parking Policies and Commuting Behavior. Transportation Quarterly, 51(1), pp. 111-125, 1997.

[12] Weinberger, R. e. (2008). Guaranteed Parking - Guaranteed Driving: Comparing Jackson Heights, Queens And Park Slope, Brooklyn Shows That A Guaranteed Parking Spot At Home Leads To More Driving To Work, University of Pennsylvania for Transportation Alternatives. www.transalt.org/files/newsroom/reports/guaranteed_parking.pdf.

[13] ISTAT, Indicatori ambientali urbani. National Institute for Statistics: Rome, 2011.

[14] Kelly, A. J., \& Clinch, P. J., Influence of varied parking tariffs on parking occupancy levels by trip purpose. Transport Policy, 6(13), pp. 487-495, 2006.

[15] Kodransky, M., \& Hermann, G., Europe's Parking U-Turn: From Accommodation to Regulation. Institute for Transportation and Development Policy: New York, 2011.

[16] Nagel, K., Still Flowing: Approaches to Traffic Flow and Traffic Jam Modeling. Operations Research, 51(5), pp. 681-710, 2003.

[17] Min, X., Hu, J., \& Zhang, Z. (2010). Urban traffic network modeling and short-term traffic flow forecasting based on GSTARIMA model. Con. Proc. of 2010 13th International IEEE Conference on Intelligent Transportation Systems (ITSC), pp. 1535 - 1540, IEEE: Funchal, 2010.

[18] Colombo, G., Pagano, F., \& Rossetti, M., Manuale di urbanistica. Strumenti urbanistici: tecnica, legislazione, procedura, giurisprudenza. Sole 24 Ore Pirola: Milan, 1996.

[19] Braess, D., Über ein Paradoxon aus der Verkehrsplanung. Unternehmensforschung, 12, pp. 258-268, 1968. 
[20] Eriksson, L., Nordlund, A. M., \& Garvill, J., Expected car use reduction in response to structural travel demand management measures. Transportation Research Part F: Traffic Psychology and Behaviour, 5(13), pp. 329-342, 2010.

[21] Litman, T., Generated Traffic and Induced Travel: Implications for Transport Planning, ITE Journal, 71(4), pp. 38-47, 2001.

[22] Raturi, A., Meredith, J., Camm, J., \& McCutheon, D., Coping with the build-to-forecast environment. Journal of Operations Management, 9(2), pp. 230-249, 1990.

[23] de Leeuw, S., Holveg, M., \& Williams, G., The impact of decentralised control on firm-level inventory Evidence from the automotive industry. International Journal of Physical Distribution \& Logistics Management, 41(5), pp. 435-456, 2011.

[24] Davis, T., Effective supply chain management. Sloan Management Review, 34(4), pp. 35-46, 1993.

[25] Pangburn, M., Balakrishnan, A., \& Stavrulaki, E., "Stack Them High, Let "em Fly": Lot-Sizing Policies When Inventories Stimulate Demand. Management Science, 50(5), pp. 630-644, 2004.

[26] Litman, T., Land Use Impacts on Transport. Victoria Transport Policy Institute. www.vtpi.org/landtravel.pdf.

[27] Stadt Zurich (www.stadt-zuerich.ch), Parking, Zurich Historic Compromise. www.stadt-zuerich.ch/parkplatzkompromiss. 